\title{
Scope for Developing Accident Causation Model of Road Transportation of Hazardous Materials
}

\author{
Ajaya Kumar $\mathbf{K}^{1}$, Tamil Selvan $\mathbf{R}^{2}$, Nehal A Siddiqui ${ }^{3}$, Ashutosh Gautam ${ }^{4}$ \\ Research Scholar, Univeristy of Petroleum and Energy Studies, Dehradun, India ${ }^{1,2}$ \\ Senior Associate Professor and Head, HSE Department, Univeristy of Petroleum and Energy Studies, Dehradun, India ${ }^{3}$ \\ India Glycols Ltd, Kashipur, Uttarakhand, India ${ }^{4}$
}

\begin{abstract}
Road accidents can happen due to various reasons related to the Driver, Vehicle and the Environment. The underlying reason for a particular accident may be a combination of various factors belonging to the above three. Based on accident analysis in detail, accident causation models can be developed. When hazardous materials (HazMat) are transported, the severity is manifold due to the additional risks due to the chemical involved. Exposure condition, flammability, spread, toxicity, threshold requirement, pressure, chances of explosion and many other specific factors are added along with the severity of a road accident. Causative factors in the road accidents are analysed which may be useful in the development of accident causation model. The contributing factors in road transportation of HazMat in Kerala also discussed, to find out the scope for developing an Accident Causation Model of road transportation of hazardous materials.
\end{abstract}

Keywords: Accident analysis, Accident Causation Model, Hazardous Materials, Transportation Risk

\section{INTRODUCTION}

A number of incidents involving the release of toxic chemicals are reported leading to serious consequences during the transportation of Hazardous Materials (HazMat). Most of the hazards can be eliminated or limited to a minimum through the use of risk analysis. A powerful tool like Transportation Risk Analysis (TRA) can be used to select the most suitable alternative with a reduced risk.

The various risk components like frequency, risk scenario, risk consequence, and likelihood are to be properly mapped with the selected route to obtain the best output (Philip, 2008). But due to the changes in urbanization, the characteristics of the neighbourhood of selected route is changing, resulting in a serious consequence.

The attributes resulting in accidents can be related to the road, vehicle, user or environment. The initiating events of accidents, the outcomes of the incident, meteorological conditions, population, time of occurrence, all have influence in determining the severity of accidents. A model incorporating the various causes of accidents and its effects on neighbourhood population during HazMat transportation based on decision support system is not available. This research is an attempt to identify the scope for linking Quantitative Risk Assessment (QRA) of HazMat during road transportation with accident causation models, using the real incident data from Kerala.

\section{BACKGROUND}

Transport operations of hazardous materials have greater risks during the entire stretch of transportation. Even if low frequency and high impact incidents are reported, it has caused in significant human loss in the industry.
Environmental damage also is very high. But, every accident is associated with different type of failures with different root causes. An analysis of the pattern of accidents and occurrence of incident with root causes can act proactively to prevent or to reduce loss or damages (Dinu, 2011)

Kerala, one of the densely populated state is having limited transportation facilities. The scope for development of the transportation sector is also limited because of the increased population density (Prasannakumar, 2011). But the hazardous material movement is taking place through the crowded routes during all times. Many incidents were reported, resulting in the human loss, time loss, damages due to pollution, traffic delay, evacuation of the neighborhood and fire. The preparedness of the society as well as the carriers is to be analysed. The probability of the risks are to be reduced and the damages to be minimised.

The factors involved in the accidents may be road, vehicle and the user (Kadiyali, 2008). The poor condition of the road, poor design features of the road, factors resulting from weather conditions, visibility problems, flow conditions, obstructions, delays etc. contribute increased chances of accidents. The poor condition of the vehicle, poor maintenance, speed parameters, control features, accelerate the chances of accidents. The behaviour of the driver, road user, fatigue, continuous driving, effect of intoxication at various levels contribute much to the accidents. While transporting hazardous materials, other than the toxicity or flammability of the material, these factors also will be contributing to the accident. The pressure conditions, temperature conditions, exposure 
levels of the chemical etc. add still more. So it is highly relevant to conduct a study on quantitative risk analysis embedded with the causes of accidents.

\section{III.NEED FOR THE RESEARCH}

The statistics published by the Government of Kerala revealed that the road accidents are increasing year by year. The urban road crashes increased by $37 \%$ from 2009 to 2012. Nearly $20 \%$ of these accidents occur at intersections (Anjana, 2015). There was an annual increase of 10 to $15 \%$ in the overall number of accidents. The accident mortality rate was increasing on an average of $15 \%$ per annum, comparing to the previous year. When we benchmark the accident statistics to a particular year, the increase is alarming.

The number of vehicles in the road is increasing every year, but the road dimensions are not changing. Flow conditions of the road is becoming unfavourable to the smooth traffic (Prasannakumar 2011). The Hazardous material transportation also is taking place through these busy streets. The reported incidents are increasing 10 to $15 \%$ per year, but the severity is manifold comparing to the benchmark years. The stakeholders affected by the incidents are seriously affected, even though the number is limited.

The guidelines and operational manuals are available to reduce the risks during transportation of hazardous materials. But detailed study correlating the accident causes and quantitative risk assessment was not taken place (Anjana, 2015). This is a humble step to investigate the scope for the correlation and development of accident causation model with QRA in transportation of HazMat.

\section{A. Objectives and scope:}

The entire research can be divided into three phases. The first phase comprises the analysis of accidents based on various parameters in selected stretches of the National Highway. This analysis will be the basis for the development of the accident causation model. The second phase comprises the analysis of accidents during hazardous material transportation in any stretch of the Highway. Third phase is the investigation to link the causative factors of the two.

The objectives are:

- To identify the basic nature of accidents happening in the selected highway stretches

-To identify the root cause of the accident based on the collected data

-To identify the features of the road contributing to the accident

-To identify the influence of road geometry with accidents

-To identify the road intersection type and the frequency of accidents

-To identify the hazards and threats from credible road accident scenarios during HazMat Transportation.

\section{B. Methodology, Area of Study and Tools}

The accident data collected from three different sections of Passive fire reduction methods during LPG transport National Highway 544 (old NH 47) was used for road suggested by Nicola P et al (2009) emphasizes how to accident cause analysis. The accidents reported from Kerala state in general used for the accidents related with hazardous material.

The CCPS-CPQRA model describes the methodology for quantitative risk analysis. IS 15656: 2006- code of practice, by Bureau of Indian Standards provides the guideline for hazard identification and risk analysis. Data analysis (primary and secondary) is done with various statistical tools.

From the collected data, the basic classification of accidents was done based on the nature of accidents for a particular period. Then basic causes behind the accidents were identified. Five specific causes and one general cause to indicate all other types was used for the analysis. Then the road features in controlling the flow was identified. After that the conditions of the road, geometric feature of identified and used in the analysis.

\section{IV.REVIEW OF LITERATURE}

Road transportation of dangerous goods, especially the aspects of Quantitative Risk assessment and route comparison is discussed by Phileppe Cassini et al (1998). The framework of the model can be developed based on this. Then the scope for incorporating decision making strategies in QRA framework to be identified. B Fabiano et al, in framework of risk assessment (2002), suggested the decision making strategies to be adopted in dangerous goods transportation. Focussed on the offsite transportation of inflammable hazardous waste materials, Arup Das et al, suggested Comprehensive risk assessment framework (2012), with a potential to establish a link materials.

After the risk assessment, then techniques to reduce the risk in various transportation system has to be analysed. Xiang Liu et al (2013) suggested the framework to improve risk reduction in rail transport system. The elements and outcomes from this study can be effectively used in the linear/segmented road transportation. The detailed guidelines for hazardous material transportation suggested by Barnhart C et al (2012) and Guidelines for QRA during transport of HazMat(2012) published by Singapore Government provides detailed insight into this area.

During transportation, in the event of a disaster or exposure, the mitigation of the disaster is important. The nature and management of disaster in the event of a HazMat incident in a transportation network was explained by James H L et al in Disaster evacuation in transport (2013). Consequence analysis can be framed from this study. Moreover, the Exposure condition analysis to reduce risk during transport of dangerous goods in rail / road transport network, suggested by Manish Verma, in "Minimisation of transport risk" (2011), helps in assessing the severity of consequences. the road and horizontal and vertical profile of the road was while assessing the risk related with the hazardous 
reduce the risk during the transport of LPG through road and rail; which can be extensively used in reducing the flammability and thereby to reduce the severity of the disaster. The risk to the environment during HazMat transportation through railway in case of a release, analysed by Mohd Rapik Saat et al (2014) resembles the situation in a linear transportation segment of a highway. This risk studies along with probability analysis of risk during transport of HazMat (Xiang Liu, 2014) can be extended to have the multivariate intersection analysis of road.

On featuring the characteristics of the accidents on roads, Asha Murali (2014) proposes the use of Information Communication Technology in reducing road accidents in Kerala. In this study, speed is considered as the root cause of general traffic accident and its controls suggested.

In the undivided highways, the randomness in the potential movement of a vehicle causing to an accident is increased, compared to the disciplined flow of lane traffic. Random parameter models are significant in such situations. R R Dinu and A Veeraragavan discusses the random parameter models for accident reduction (2011) for considering in the prediction of two lane undivided highways.

The fatality of accidents is not depended on the time at which it has happened. But the chances of survival of a victim highly depends on the minimum response time and the proper attention available to him/her in the minimum time. The traffic congestions, in one way increases the attention time and delays the rescue operations while odd time incidents delay the attention as well as rescue. The indicators available to the rescue team also is important. An in depth analysis for the scope for researching fatality rate reduction with evidence for time invariance and state specificity was done by Raj V P in Road traffic fatalities studies (2012).

In signalised intersections, the randomness of the vehicular movement is avoided and a controlled movement only is permitted. The stream and flow is predetermined and the time of flow also is decided. In such cases the chances of accidents are merely due to violation of the flow behaviour or unlawful entry to the stream other than the sudden vehicular failures. Severity of the accidents in such intersections can be analysed at specific crash severity levels. Abdel et al (2005), identified the scope and potential of the analysis of specific crash severity levels at signalised intersections.

Accident spot studies reveal that there is a clear time gap between the occurrence of accidents (crash) and the spontaneous response towards a potential accident. Many factors including the conditions of the vehicle, environment and driver behaviour acts before the crash. If parametric estimation of these factors can be made, then prediction of the crash is possible; but not complete avoidance of the crash. A probabilistic approach of crash prediction, Bayesian hierarchical approach of prediction models, was suggested by Huang $\mathrm{H}$, in his Crash prediction model (2008). But it is highly mathematical in nature and the practical relevance as well as usefulness has to be proved yet at various accident spots at various environments.

Accident severity depends upon many factors. The data collected from the accident spot as well as from the interrogating agencies will give an insight. In many cases the data entered in the insurance files also reveal many contributing factors. Severity analysis is complex because of the variables and their interrelations. Rifaat $\mathrm{S}$ et al, generated accident severity analysis (2005), using Probit model. The way in which the complexities are related to the particular accident scenario may not be a replica of a repeated accident in another topography and climatic conditions, where the model has its major limitations; and the severity classification in various countries are not the same.

Identification of the accident hotspots was another concern. If the number of accidents happening in the same spot or in the same stretch are more, it was considered as the accident hotspots. The characteristics of the accidents and remedial measures can be thought of, if clustering of accidents are made. Prasannakumar V et al, in their approach of spatiotemporal clustering of accidents (2011), made a significant attempt to identify accident hot spots by GIS analysis and clustering. Only a small area was brought under the study and and there is a scope to include it in the longitudinal stretches of the highways.

Roundabouts are always vulnerable spots for accidents. The "speed non-reduction tendency" of the approaching vehicles seems to be a significant cause in majority of the accidents in roundabouts. The design parameters like roundabout radius, the lane width, extra width required for the alignment changes, etc. are to be dealt with proportional significance. Anjana S et al (2014), tries to have a safety evaluation tool for roundabouts, using statistical techniques incorporating more geometric variables with a potential scope for accident prediction models.

\section{ANALYSIS}

\section{A. General Road Accidents}

Based on the accident data collected from three different stretches of National Highways in Kerala, the nature of accidents was analysed. Details of the accident data collection points are provided in Table 1.

TABLE I: DETAILS OF ACCIDENT DATA

\begin{tabular}{|c|l|c|}
\hline Road & \multicolumn{2}{|c|}{ National Highway 544 (Old NH47) } \\
\hline Period & \multicolumn{2}{|c|}{ 21.06.2014 to 26.07.2015 } \\
\hline $\begin{array}{l}\text { Road } \\
\text { Section }\end{array}$ & Study Area Location & $\begin{array}{l}\text { Number of } \\
\text { accidents }\end{array}$ \\
\hline 1 & Walayar- Vadakkancherry & 74 \\
\hline 2 & Vadakkancherry - Thrissur & 89 \\
\hline 3 & Thrissur- Angamaly & 82 \\
\hline
\end{tabular}

The nature of accidents were classified as Overturning, Head on Collision, Rear End Collision, Side Wipe, Right Turn Collision and Skidding and the percentages of each category in the respective sections are given in Fig.1 to Fig.3. A comparison of the nature of accidents in all the three sections is given in Fig. 4 . 
Head on collision is the dominat factor in Higway Section 1 and 3, while rear end collision is dominant in Section 2. Comparing all the three sections, it is evident that the collision from front or back (head on collision as well as rear end collision) is the major factor $(65 \%, 76 \%$ and $59 \%$ respectively).

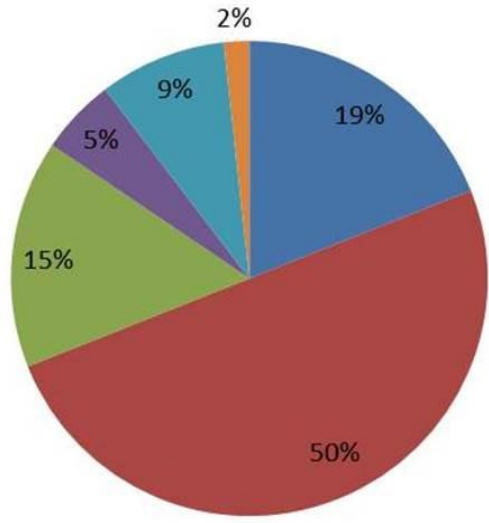

- Overturning

Head on collision

Rear End Collision

- Side Wipe

E Right Turn Collision

= Skidding

Fig. 1. Nature of accidents in Study Area Section 1

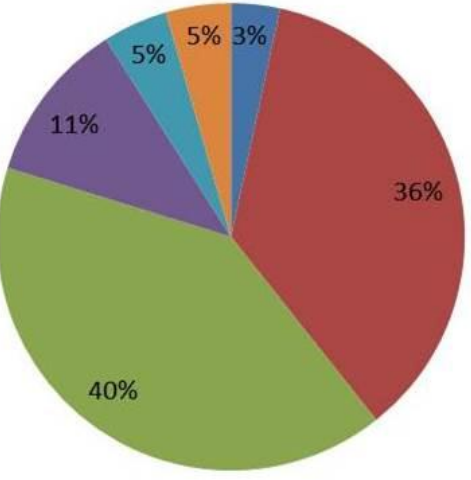

n Overturning

- Head on collision

Rear End Collision

- Side Wipe

night Turn Collision

- Skidding

Fig. 2. Nature of accidents in Study Area Section 2

The root cause of the accident has to be understood for taking any control measures. Driving the vehicle in an intoxicated condition either by the influence of alcohol or some alternatives, Over speeding of the vehicles, Vehicle going out of control due to various reasons, Various faults (such as faults of the driver of the vehicle, faults of the driver of the other vehicle, unpredicted sudden movements of the cyclists, unpredicted movement of the pedestrians, unpredicted actions of the passengers), Defects in the mechanical condition of the road or the vehicle are some of them.

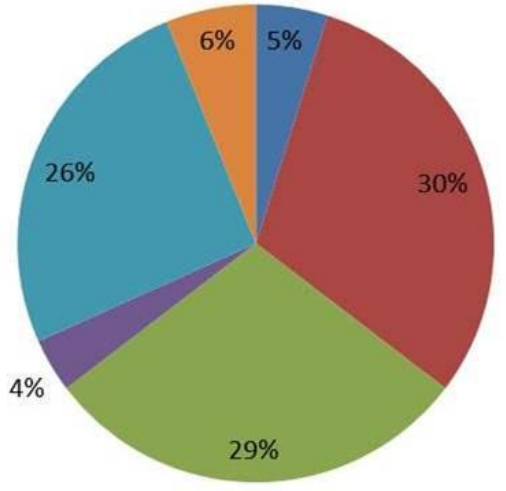

\section{averturning}

- Head on collision

- Rear End Collision

- Side Wipe

Right Turn Collision

- Skidding

Fig. 3. Nature of accidents in Study Area Section 3

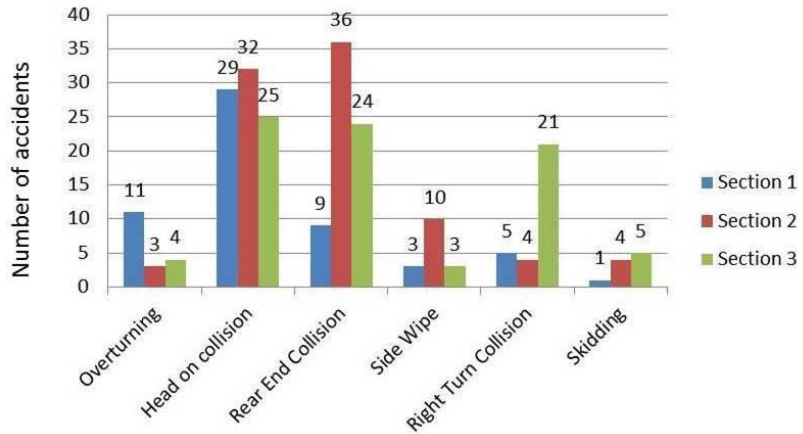

Fig. 4. Nature of accidents in all the sections of Study Area

The percentage contribution of these causes are given in Fig.5, Fig.6, Fig.7 and a comparison is given in Fig.8.

The overall contribution of the overspeeding to cause accidents are $74 \%, 33 \%$ and $56 \%$ in the respective sections, emphasizing the featured characteristics of the accidents on roads by Asha Murali (2014). Here also, in the studied cases $53.06 \%$ of the accidents are because of overspeeding.

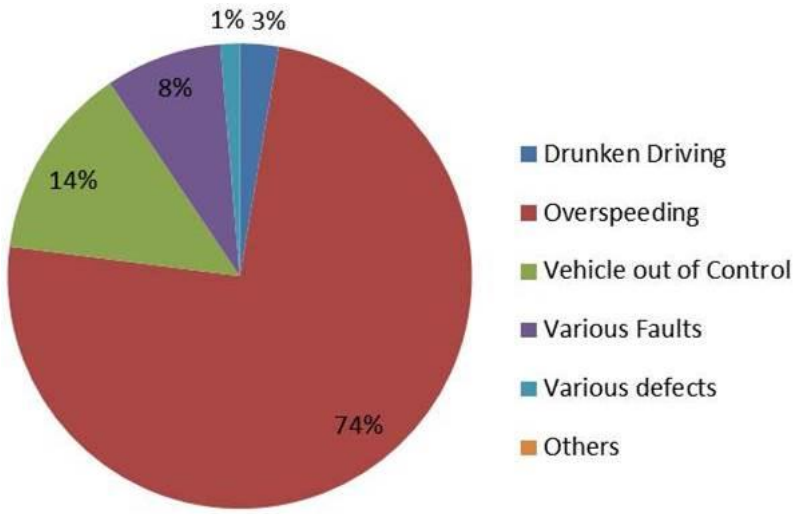

Fig. 5. Causes of accidents in Study Area Section 1

The features of the road has great influence in the development of an incident into accident. The characteristics of the flow highly influences in resulting accidents depending on the road profile. The accident cases with the road profile as single lane, two lane, three or more lanes without median and three or more lanes with median are compared in Fig.9. The general trend indicates more number of accidents in two lane road where the lanes are not separated with medians.

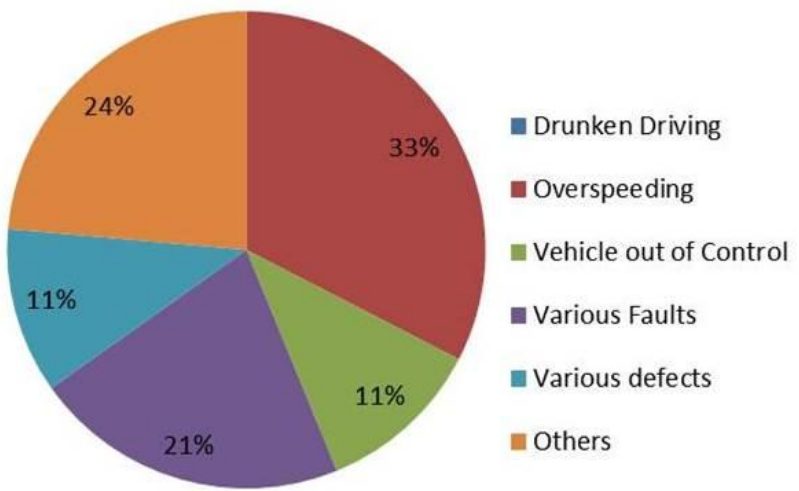

Fig. 6. Causes of accidents in Study Area Section 2 


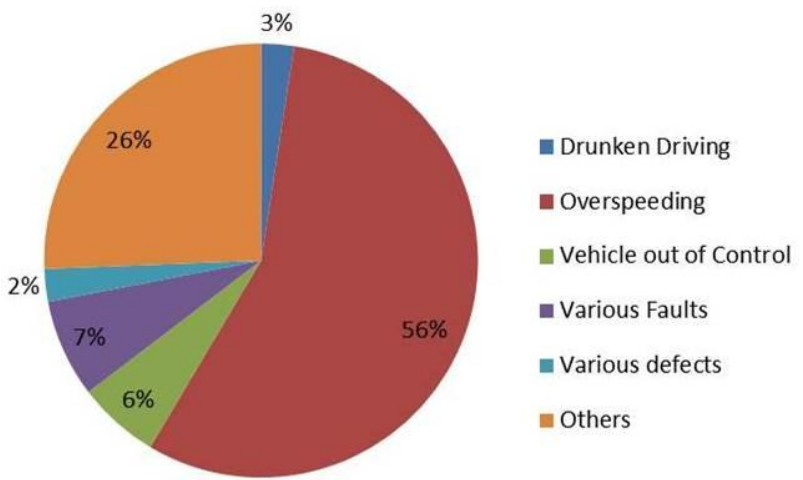

Fig. 7. Causes of accidents in Study Area Section 3

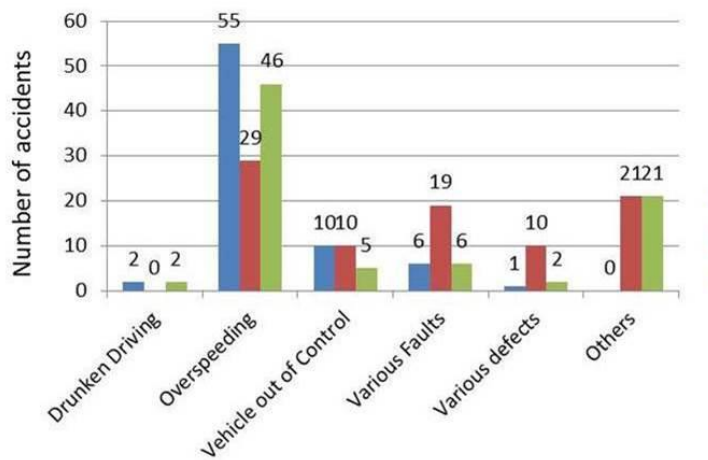

Fig. 8. Causes of accidents in all the sections of Study Area

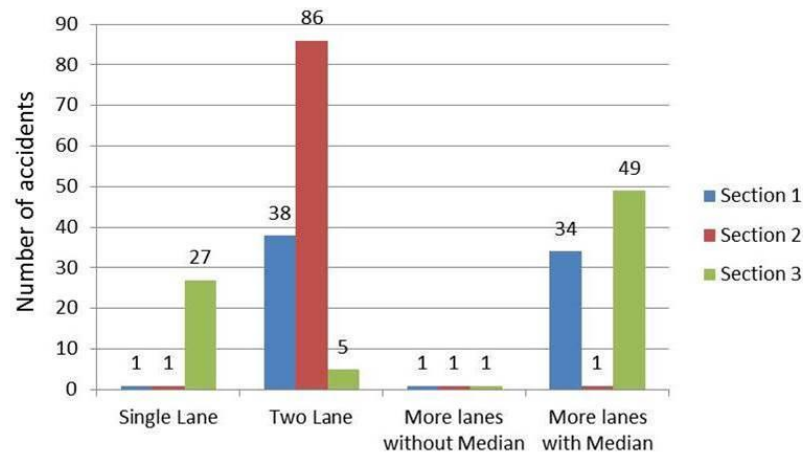

Fig. 9. Accident Analysis based on Road Condition

The condition of the road and its geometry either in the vertical plane or in the horizontal plane contributes much. The comparative analysis of the accidents happened in Straight road, Road with slight curve, Road with sharp curve, Flat road and Road with a gentle incline are compared in Fig.10. The figures indicate the fact that drivers take more care in sharp curves comparing to the slight curves. Indirectly the chances of accidents are more in a slight curve than a sharp curve because the slight curve seems to be nominal deviation from the continuity of straight line psychologically, resulting in the accidents.

The road intersection type and the entry, such as $\mathrm{T}$ junction, $\mathrm{Y}$ junction, Four arm junction, Staggered junction and other types including the roundabouts are shown in Fig.11. More number of accidents are indicated in the $\mathrm{T}$ junctions because of the increased number of conflict points at the time of entry or exit from the junction.

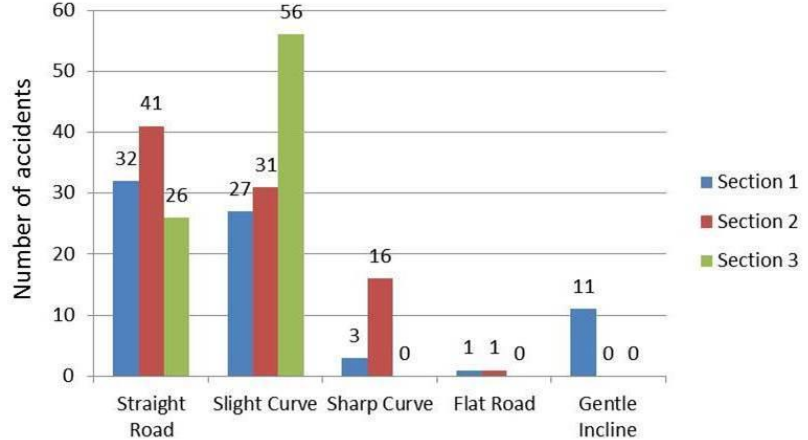

Fig. 10. Accident Analysis based on Road Geometry

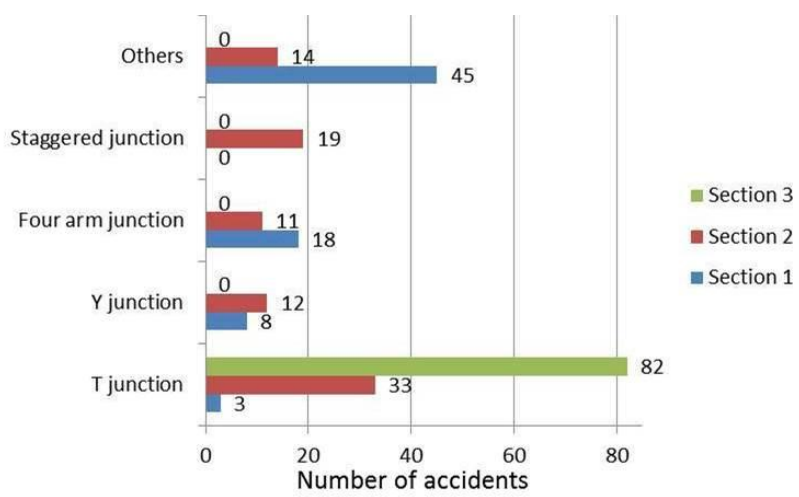

Fig. 11. Accident Analysis based on Road Intersection type

\section{B. Accidents with hazardous material transportation}

The accident data used in the above analysis does not make any specific mention about the hazardous material transportation and the involvement of such materials in accidents. So secondary sources were selected to identify such accidents in Kerala. Instead of the specific stretch selected, entire Kerala state was selected as the site for data collection.

A serious accident involving the hazardous materials transportation was reported on December 31, 2009, in which seven people lost their lives when the LPG transported in a tanker exploded at Karunagapally in Kollam district [21].

Next serious accident was on August 27, 2012 in which an LPG carrier had burst into flames at Chala in Kannur district, [22] killing 20 persons and injuring many. A similar incident reported on January 7, 2014, near Angamaly, Ernakulam in which a gas leak in an LPG tanker on the National Highway triggered panic among the local people.

Also on January 14, 2014, at Kallyasseri in Kannur a bullet tanker lorry carrying 18 tons of LPG overturned and caught fire on the National Highway in the early morning hours, forcing residents in the area to run away from their homes in panic. But because of the preparedness of the people from the Chala incident reduced the severity, and made the life loss to zero. [23]

The existing highway which does not have proper geometrics, including smooth curves, resulted in the 
incident. The vehicle density expressed in average passenger car unit (PCU) counted on a two lane $\mathrm{NH}$ here in this region is 40,000 , theoretically only a four-lane road can cope with that rate of vehicle density. [22,24]

Generally, in a bullet tanker, the LPG is filled and transported as "liquid under high pressure". On accidental release, it quickly vaporises into highly combustible gas which can catch fire or explode. Most gas leaks and explosions are caused by damage to the valves that control the flow of LPG from the tanker. The heavily populated areas along the sides of the National Highway in Kerala enhance the vulnerability factor. It is very difficult to contain the leaking gas except with specialised equipment.

The State Disaster Management Authority (SDMA) has identified that large parts of the state are considered vulnerable to the hazards of LPG tanker accidents. The State has only one specialised emergency rescue vehicle based in Ernakulam, equipped to plug an LPG leak or transfer gas from a stricken tanker, or to manage other chemical accidents.

Comparing to the general road accident cases, the accidents with HazMat is also similar in happening, when we consider the initial part. But the severity of the accident is increasing just after the accident due to the release of hazardous chemicals and its consequence.

Based on the general road accident data, many accident causation models were suggested. In these accident causation models, the framework of accident description starts with the Driver-Vehicle-Environment model (DVE model) which is the most accepted one. In the functional point of view, the DVE system processes were explained through Human Functional Failure (HFF) model. Later, 'On The Spot' (OTS) model was suggested. In all these models, various parameters as we discussed in the accident scenario only was considered. The causative factors during hazardous material transportation was not specifically mentioned in these models. Establishing a link between the two models, general accident causation model of hazardous materials and accident causation model of transportation systems is the need of the hour.

\section{VI.CONCLUSION}

The accident causation model for general transport system is available in various countries according to the climatic conditions and territorial characteristics. Accident causation studies with hazardous materials (handling, packing, filling, carrying etc.) also is available. But accident causation model with specific reference to the HazMat during transportation is not available. The intersection analysis incorporating the transportation risks of HazMat is seldom available. In this study, the causative factors of general road accidents were analysed, which will be the basis of any Accident causation model. Then the additional factors contributed in the accidents during road transportation of HazMat in a mix of variety of road conditions discussed. Scope for developing an accident causation model during hazardous material transportation was explored. If extensively developed, the proposed accident causation model, can be extensively used for replanning the intersections, modifying the road contours with varying topographies, channelizing or segmenting the traffic at potential hot spots with proper consideration to the hazardous material transportation. Moreover, the traffic analysis with single lane conditions, multilane conditions, two directional flow conditions, etc. also can be made specific with the associated risks. Various control measures also can be planned based on the analysis. The causation model prioritize the root causes of an accident, which will be useful to control/manage the present transport risks and to refine future TRA studies. Also it will be useful to identify and to establish points of strategic importance in the emergency responses based on IVMS input during HazMat transportation.

\section{ACKNOWLEDGMENT}

The authors thankfully acknowledges the timely help and services provided by the officers of National Highway Authority of India (Kerala section) and Kerala Police during the guideline data collection and analysis.

\section{REFERENCES}

[1] Abdel Atu M A, Keller J, "Exploring the overall and specific crash severity levels at signalised intersections", in Accident Analysis and Prevention 37(3) 2005, pp 417-425.

[2] Anjana S, Anjaneyulu MVLR, "Safety analysis of urban signalised intersections under mixed traffic", in Journal of Safety Research 52 (2015), pp 9-14

[3] Arup Das, A K Gupta, T N Mazumder, "A comprehensive risk assessment framework for offsite transportation of inflammable hazardous waste" in Journal of Hazardous Materials 227-228 (2012), pp 88-96.

4] Asha M, AjayaKumar, "Adoption of information and communication technology in road accident reduction" in International Journal of Computer science and Network, Vol.3, Issue 2, 2014, pp180-188.

[5] Dinu R R, A Veeraragavan, "Random parameter models for accident prediction on two lane undivided highways in India" in Journal of Safety Research 42 (2011), pp39-42.

[6] Erhan Erkut, Stevanus A T, Vedat V, C Barnhart(ed), G Laporte (ed),"Hazardous Material Transportation", Handbook in OR and MS, Vol.14.

[7] Fabiano B, F Curro, E Palazzi, R Pastorino, "A framework of risk assessment and decision making strategies in dangerous good transportation" in Journal of Hazardous Materials 93 (2002) pp 115 .

[8] Huang H, Chin H C and Haque M M, "Bayesian hierarchical analysis of crash prediction models", Proceedings of the 87th annual meeting of Transportation Research Board Washington DC, USA (2008)

[9] James H L, Ayse I P, Qian Z, John S M, Michael D F, Thomas M G, Janet L C, Shital A T, "Understanding and managing disaster evacuation on a transportation network" in Accident Analysis and Prevention 50 (2013), 645-658.

[10] Kadiyali L R, Traffic Engineering and transport planning, (2008)

[11] Manish Verma, "Railroad transportation of dangerous goods: A conditional exposure approach to minimize transport risk" in Transportation Research Part C 19 (2011) , pp 790-802

[12] Mohd R S, Charles J W, David S, Hongkyu Y, Christopher P L B, "Environmental risk analysis of hazardous material rail transportation" in Journal of Hazardous Materials 264 (2014), pp 560-569.

[13] Nicola P, Gabriele L, Menso M, Sarah B, Gigliola S, Valerio C, "Risk reduction in road and rail LPG transportation by passive fire protection" in Journal of Hazardous Materials 167 (2009) , pp 332-344.

[14] Philip Cassini, "Road transportation of dangerous goods: quantitative risk assessment and route comparison " in Journal of Hazardous Materials 61 (1998) , pp 133-138. 
[15] Prasannakumar V, Vijith H, Charutha R, Geetha N, "Spatio temporal clustering of Road Accidents: GIS based analysis and assessment" in Procedia Social and Behavioral Sciences 21 (2011) , pp 317-325.

[16] Raj V Ponnulari, "Modelling road traffic fatalities in India: Smeed's law, time invariance and regional specificity" in International Association of Traffic and Safety Sciences Research, 36 (2012), pp 75-82.

[17] Rifaat S M, Chin H C, "Accident severity analysis using ordered Probit model" in Journal of Advanced Transportation 41(1) 2005 , pp 91-114.

[18] Xiang Liu, M Rapik Saat, CPL Barkan, "Integrated risk reduction framework to improve railway hazardous materials transportation safety" in Journal of Hazardous Materials 260 (2013) , pp 131-140

[19] Xiang Liu, Mohd R S, Christopher PLB, "Probability analysis of multiple tank car release incidents in railway hazardous materials transportation" in Journal of Hazardous Materials 276 (2014), pp 442-451

[20] Guidelines for quantitative risk assessment, Pollution Control Department, NEA, Singapore.

[21] The Hindu, Kerala edition [Online] Available: http://www.thehindu.com/news/national/kerala/kerala-illequippedto-tackle-lpg-tanker-accidents/article5571904.ece

[22] The Hindu, Kerala edition [Online] Available: http://www.thehindu.com/news/national/kerala/wakeup-calls-fallon-deaf-ears/article5589956.ece?ref=relatedNews

[23] The Hindu, Kerala edition [Online] Available: http://www.thehindu.com/news/national/kerala/lpg-tanker-lorryexplodes-causes-huge-fire-nearkannur/article3828866.ece?ref=relatedNews

[24] The Hindu, Kerala edition [Online] Available: http://www.thehindu.com/news/national/kerala/driver-dead-aftertanker-falls-into-field/article7436635.ece

[25] National Highways Authority of India web site [Online] Available: www.nhai.org.in 